\title{
Pagamento por Serviços Ambientais de Recursos Hídricos na Região Centro-Oeste do Brasil: uma abordagem crítica da perspectiva coaseana
}

\author{
Payment for Environmental Water Resources Services in Midwest Brazil: a \\ Critical Approach from the Coasean Perspective
Pago por Servicios Ambientales de recursos hídricos en el Centro-Oeste de Brasil: un enfoque crítico desde la perspectiva "coeseana"

\author{
Fábio Melges ${ }^{1}$ \\ Leonardo Francisco Figueiredo Neto ${ }^{1}$ \\ Élcio Gustavo Benini ${ }^{1}$
}

Recebido em: 29/10/2019; revisado e aprovado em: 28/01/2020; aceito em: 11/03/2020

DOI: http://dx.doi.org/10.20435/inter.v22i3.2789

\begin{abstract}
Resumo: O reconhecimento dos serviços ecossistêmicos para o bem-estar da sociedade vem sendo amplamente divulgado no meio científico, assim como é perceptível que o interesse da população quanto a sua relevância tem aumentado expressivamente. Este trabalho apresenta como objeto de investigação o Pagamento por Serviços Ambientais (PSA), sendo este considerado um instrumento de gestão ambiental capaz de gerar valor econômico a partir da proteção e manutenção de ecossistemas por meio de incentivos econômicos a "provedores" de serviços ambientais. Considerando-se que o PSA se materializa por intermédio de contratos, este trabalho analisou seus pressupostos teóricos, bem como os elementos institucionais que formam um mercado de PSA e sua utilização como ferramenta de política pública ambiental. Para tanto, foram investigados dois projetos no âmbito do Programa Produtor de Água da Agência Nacional de Águas (ANA), por meio das seguintes dimensões de análise: os arranjos institucionais; a metodologia de remuneração; custo de oportunidade; o monitoramento; e a eficiência dos projetos. Os resultados demonstraram que, embora o PSA seja apresentado como uma ferramenta genuína de mercado, na prática os esquemas são formados por múltiplos agentes, o que implica uma reformulação de seu marco conceitual de questões ligadas à propriedade privada para uma perspectiva mais abrangente que parta do trabalho: o serviço ambiental. Também foi identificado que as mensurações da efetividade dos custos associados ao programa em comparação com outras políticas ambientais são pouco exploradas no campo de estudos dos serviços ecossistêmicos, podendo levantar dúvidas da potência do instrumento na indução de comportamentos e preservação ambiental.
\end{abstract}

Palavras-chave: políticas públicas; serviços ecossistêmicos; pagamento por serviços ambientais.

Abstract: The recognition of ecosystem services for the welfare of society has been widely disseminated within the scientific community, as well as the interest of the population regarding its relevance has increased significantly. This paper presents as an object of investigation the Payment for Environmental Services (PES), which is regarded as an instrument of environmental management capable of generating economic value from the protection and maintenance of ecosystems through economic incentives to environmental services "providers". Considering that PES materializes through contracts, this paper has analysed its theoretical assumptions as well as the institutional elements that form a PES market and its use as a tool for environmental public policy. Thus, two projects under the Water Producer Program of the National Water Agency (ANA) were investigated, through the following dimensions of analysis: the institutional arrangements; a remuneration methodology; opportunity cost; monitoring; and efficiency of the projects. The results demonstrate that although PES is viewed as a genuine market tool, in practice the schemes are agent-driven, which implicates in a redesign of its conceptual framework of issues that may be linked to private property to a broader perspective that comes from the environmental service. It has also been identified that cost-effectiveness measurements associated with the program in comparison to other environmental policies are poorly explored in the field of ecosystem service studies, which may cause doubts on the power of such an instrument in behaviour induction and environmental conservation.

Keywords: public policies; ecosystem services; payment on environmental services.

Resumen: El reconocimiento de los servicios ecosistémicos para el bienestar de la sociedad se ha difundido ampliamente en la comunidad científica, y también es evidente que el interés de la población con respecto a su relevancia ha aumentado significativamente. Este documento presenta como objeto de investigación

\footnotetext{
${ }^{1}$ Universidade Federal de Mato Grosso do Sul (UFMS), Campo Grande, Mato Grosso do Sul, Brasil.
} 


\begin{abstract}
el Programa Pago por Servicios Ambientales (PSA), que se considera un instrumento de gestión ambiental capaz de generar valor económico a partir de la protección y mantenimiento de los ecosistemas a través de incentivos económicos a los "proveedores" de servicios ambientales. Teniendo en cuenta que el PSA se materializa a través de contratos, se ha analizado sus supuestos teóricos, así como los elementos institucionales que forman un mercado de PSA y su uso como herramienta para la política pública ambiental. Con este fin, se investigaron dos proyectos en el Programa de Productores de Agua de la Agencia Nacional del Agua (ANA), por intermedio de las siguientes dimensiones de análisis: los arreglos institucionales; la metodología de remuneración; costo de oportunidad; el monitoreo; y la eficiencia de los proyectos. Los resultados mostraron que, aunque el PSA se presenta como una verdadera herramienta de mercado, en la práctica los esquemas están compuestos por múltiples agentes, implicando en una reformulación de su marco conceptual de cuestiones de propiedad privada a una perspectiva más amplia basada en el trabajo: el servicio ambiental. También se identificó que las mediciones de costo-efectividad asociadas con el programa en comparación con otras políticas ambientales son poco exploradas en el campo de los estudios de servicios ecosistémicos, lo que puede generar dudas sobre el poder de este instrumento en la inducción de comportamiento y la preservación del medio ambiente.
\end{abstract}

Palabras clave: políticas públicas; servicios ecosistémicos; pago por servicios ecosistémicos.

\title{
1 INTRODUÇÃO
}

Serviços Ecossistêmicos (SE) são a capacidade que os ecossistemas têm de oferecer benefícios e bem-estar à humanidade e incluem-se alimentos, combustíveis, madeira, fornecimento de água, purificação do ar, reciclagem natural de resíduos, formação do solo, entre outros (MILLENIUM ECOSYSTEM ASSESSMENT [MEA], 2005). É importante apontar a diferença entre os conceitos de serviço ecossistêmico e de serviço ambiental. O primeiro está ligado diretamente aos serviços de suporte à vida prestados pela natureza; é bem amplo e incorpora benefícios tangíveis e intangíveis. Quanto aos serviços ambientais, são os relacionados à atividade humana ligada ao aumento ou à manutenção da provisão de serviços ecossistêmicos, como práticas conservacionistas e de manejo e mudanças no uso da terra, por exemplo, sendo possível a remuneração por tal atividade (CHOMITZ; BRENES; CONSTANTINO, 1999; SIMÕES; ANDRADE, 2013).

Baseado no teorema² de Coase (1960), Wunder (2005) arquitetou o conceito de Pagamento por Serviços Ambientais (PSA) como um contrato entre um proprietário de determinada área que adota práticas seguras de conservação e restauração de ecossistema para a manutenção de serviços ecossistêmicos em troca de pagamentos efetuados pelos beneficiários externos dessas práticas. Para Guedes e Seehusen (2011), o PSA é uma transação voluntária entre um proprietário de um ativo que forneça SE e um outro agente para garantir a continuidade do serviço em detrimento de outra atividade econômica.

A conceituação deixa nítidas as premissas da política de PSA que sustentam sua perspectiva de um instrumento econômico de mercado. É importante destacar que a ontogênese do PSA ocorreu a partir da crise econômica que marcou a década de 1970 (HARVEY, 2008), dando início a uma série de reformas e agendas liberais, assim como políticas públicas com maior participação da sociedade (OSBORNE; GAEBLER, 1994).

É nesse contexto que o PSA começou a ganhar notoriedade. O caso de sucesso publicado na revista Nature em 1988, o programa de PSA de Nova York, alcançou repercussão internacional. Sua ampla divulgação fortaleceu argumentos pró-mercado e novos mecanismos de preservação ambiental no âmbito internacional (BLANCHARD; VIRA; BRIEFER, 2015).

\footnotetext{
${ }^{2}$ Coase (1960) advoga que o bem-estar social pode ser maximizado mediante transações voluntárias das externalidades via mercado (entre compradores e vendedores), quando os direitos de propriedade estão bem definidos.
} 
Simões e Andrade (2013) advertem que há questionamentos a respeito da base conceitual e teórica dos PSAs. Os autores defendem que tal mecanismo, ao ser excessivamente direcionado para aspectos mercadológicos, transformam serviços ambientais em commodities, negligenciando outros fatores relevantes, como a complexidade e diversidades contextuais dos SE. Um relatório feito pela Organização das Nações Unidas para a Alimentação e a Agricultura (FAO) reportou que o programa tem sua base teórica conceitual amparada por pressupostos da economia neoclássica e no teorema de Coase; tal conclusão pressupõe um princípio utilitário e orientado para e pelo mercado, o que pode levar a uma não compreensão da importância de um determinado ecossistema, baseado apenas na disposição a pagar de um elemento consumidor (FAO, 2011).

Por seu turno, Blanchard, Vira e Briefer (2015) e Pascual et al. (2009) questionam mecanismos de PSA como estratégia de conservação ambiental, argumentando que eles estão inseridos dentro de uma lógica que constrói narrativas de mercado como a solução para questões ambientais, sem, contudo, demonstrar resultados melhores do que as práticas conservacionistas regulatórias mais tradicionais, além de deixar em segundo plano complexas relações sociais envolvendo políticas públicas, bens ambientais e os agentes envolvidos com tais questões.

Além dos questionamentos sobre a perspectiva de mercado para questões ambientais, são também apontados problemas na própria consideração do mecanismo de transação dos SA como um "produto puro" de mercado (no sentido estrito do termo). Landel-Mills e Porras (2002), por exemplo, ressaltam que, em mercados tradicionais, é fácil definir uma commodity; elas estão em todo lugar e são fáceis de identificar. Porém, no caso de serviços ambientais, tal identificação ou mensuração é um desafio. Serviços individuais não conseguem necessariamente ser traduzidos como commodities.

A despeito da narrativa acerca da eficiência do instrumento de mercado PSA, é possível verificar empiricamente se a sua aplicação corrobora a narrativa de mercado e a perspectiva coaseana? Dessa forma, considerando que o PSA se materializa por intermédio de contratos, assim como sua inspiração no sistema teórico de Coase, este trabalho analisa os elementos institucionais que formam um mercado de PSA e sua utilização como ferramenta de política pública ambiental. Especificamente, realiza uma abordagem crítica dos pressupostos teóricos do PSA, bem como verifica a base conceitual do programa Produtor de Água e sua eficiência, sendo este o campo empírico-particular estudado.

Para verificar a eficiência do mecanismo PSA, foram observados ${ }^{3}$ fatores como custos de transação e oportunidade, arranjos institucionais, efeito de permanência, vazamento e adicionalidade em programas de PSA voltados à conservação de recursos hídricos na Região CentroOeste do Brasil, sendo o campo empírico constituído de dois projetos no âmbito do Programa Produtor de Água da Agência Nacional de Águas (ANA), cuja descrição está exposta na seção de procedimento metodológico.

A discussão deste trabalho estrutura-se da seguinte forma: são abordadas as temáticas referentes às políticas públicas ambientais, seguidas de um breve histórico de mercados de PSA e serviços de ecossistemas, e uma discussão a respeito da abordagem multicêntrica para PSA; na sequência, são apresentados a metodologia, os resultados e as considerações finais.

\footnotetext{
${ }^{3}$ Conforme sugestão de análise de Engel, Pagiola e Wunder (2008) e Santos e Silvano (2016).
} 


\section{POLÍTICAS AMBIENTAIS}

As questões ambientais estão diretamente ligadas às questões econômicas e sociais. Para MEA (2005), a degradação dos ecossistemas afeta o crescimento econômico de países em desenvolvimento e faz surgir ou agravar a pobreza da população destes países, além de contribuir para o surgimento de conflitos. Para FAO (2011), a conservação de ecossistemas é uma proteção contra a pobreza e a insegurança alimentar e contribui para o bem-estar humano em geral. Estudo de Stern (2006) demonstrou que postergar ações de mitigação dos impactos na mudança climática é mais caro do que atuar imediatamente, e que prejuízos com catástrofes ambientais são cada vez mais frequentes e de maior intensidade.

Para mitigar os danos causados ao meio ambiente, o Estado faz uso de políticas ambientais que consistem em um conjunto de princípios, intenções e metas que objetivam diminuir os impactos negativos das ações antropogênicas sobre o meio ambiente. São constituídas de estímulos a quem internaliza seus custos sociais, conhecidos como Instrumentos Econômicos, e/ ou de punições ligadas a algum tipo de atividade que cause impacto negativo ao meio ambiente, conhecidos como Instrumentos de Comando e Controle (BRASIL, 2017).

Políticas públicas são instrumentos de ação dos governos (HÖFLING, 2001). Elas são influenciadas pelas instituições (IKENBERRY, 1994) e são configuradas a partir da validade e legitimidade de uma ideia institucionalizada (subjacente) àquela política estabelecida (MUNCK; SOUZA, 2009). Para Souza (2006), é possível considerar política pública como um ciclo deliberativo e dinâmico que é constituído pelo estabelecimento de uma agenda, identificação de possíveis alternativas, avaliação e seleção das opções e, finalmente, pela implementação da política pública e sua posterior avaliação.

De acordo com Ikenberry (1994, p. 7), cenário institucional é o "resultado de uma confluência histórica de forças que dão forma e remodelam a estrutura organizacional do estado" que faz a mediação da luta na política moderna. As instituições moldam as ações dos atores políticos e estruturam as relações de poder entre os grupos, e a análise institucional permite examinar a relação destes atores como agentes produtores e produtos da história (THELEN; STEINMO, 1992). Para Dimaggio e Powell (1991), os atores e seus interesses são construídos institucionalmente, e assim são definidos os fins e modelados os meios pelos quais os interesses são determinados e perseguidos.

\section{O MERCADO DE PAGAMENTO POR SERVIÇOS AMBIENTAIS (PSA)}

Um ecossistema é uma combinação complexa e dinâmica de plantas, animais e microrganismos que vivem em conjunto, como uma unidade, e têm uma dependência mútua. Os ecossistemas oferecem à humanidade uma ampla variedade de benefícios conhecidos como "bens e serviços ecossistêmicos", tais como alimentos (carne, peixe, legumes etc.); combustíveis e madeira; água e purificação do ar; reciclagem natural de resíduos; formação do solo; e a polinização e os mecanismos de regulação que a natureza, por si mesma, utiliza para controlar as condições climatéricas e as populações de animais, insetos e outros organismos. Essas capacidades são definidas como serviços ecossistêmicos quando contribuem para o bem-estar da sociedade (MEA, 2005; SANTOS; SILVANO, 2016).

Partindo de uma premissa econômica que busca internalizar custos ambientais no manejo de propriedades onde existam bens ecossistêmicos, o PSA busca dar uma resposta de mercado 
ao problema do fornecimento de SE. Wunder (2005) afirma que a ideia central desses programas é o pagamento direto, amparado em contratos, ao proprietário do ativo ambiental, pelos beneficiários externos, para que aquele adote práticas seguras de manejo de conservação e restauração do ecossistema.

O princípio para a construção de uma política de PSA é a comprovação de práticas conservacionistas que acarretam benefícios adicionais para a sociedade e, diretamente, para agentes que usufruem da redução de custo ou melhoria da qualidade de insumos necessários aos seus próprios processos produtivos. Porém, como esses serviços ambientais não são precificados, o mercado "falha" em não retribuir ao protetor-conservador um benefício por sua ação ter gerado bem-estar a terceiros. Essa política destina, então, corrigir essa falha, remunerar, de alguma maneira, a ação que conserva o serviço ambiental (ANA, 2012; BROUWER; TESFAYE; PAUW, 2011). Na figura 1, é possível verificar o funcionamento do mercado de PSA:

Figura 1 - funcionamento do mercado de PSA

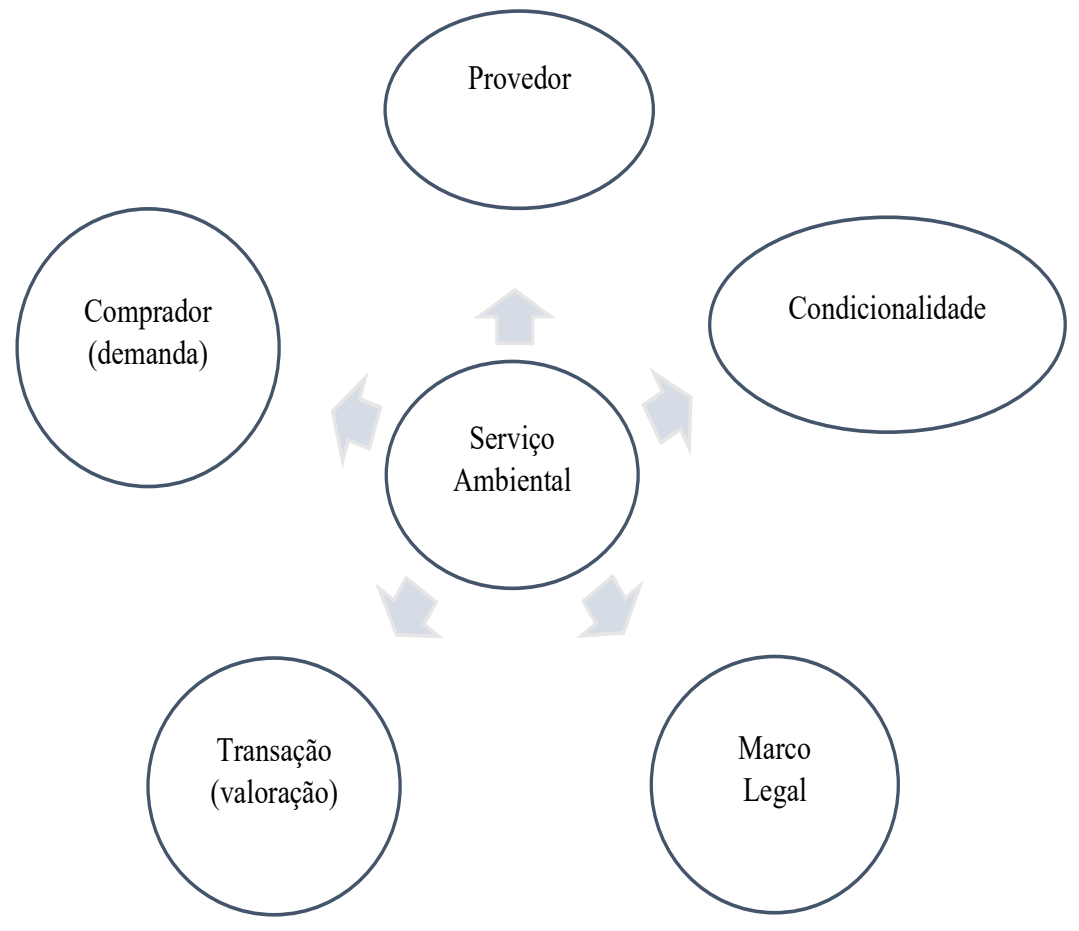

Fonte: Adaptado de Guedes e Sehusen (2011).

Ao fim dos anos 1970 e início dos anos 1980, a estratégia dominante de conservação da natureza e de ecossistemas específicos era a regulação. Contudo, a partir dos anos 1980, nos períodos dos governos "Carter e Reagan", em que ocorreu uma forte conversão do pensamento para questões orientadas ao mercado, novas programas e políticas ambientais que defendessem uma visão mercadológica encontravam lastro ideológico e espaço para que fossem implantados (BLANCHARD; VIRA; BRIEFER, 2015).

Em 1995, foi apresentado pela Intergovernmental Panel on Climate Change (IPCC) um relatório que demonstrava, pela primeira vez, que os efeitos do aumento da concentração de gases de efeito estufa era correlacionado com o aquecimento global. Tal fenômeno vem ocorrendo desde a revolução industrial decorrente de atividades antropogênicas e, segundo o relatório, 
o aumento da concentração de gases foi de 70\% entre 1970 e 2004. Esse cenário resultou na assinatura do Protocolo de Kyoto, em 1997, que instaurou uma rede institucional internacional para tentar regular e criar um mercado de carbono e que objetivava reduzir e refrear os impactos negativos do efeito estufa. Tem-se nesse protocolo a gênese do mercado global de serviços ecossistêmicos que compõem o mercado de carbono, o mercado de serviços hídricos e o mercado da biodiversidade. O destaque entre os países é a Costa Rica, o primeiro país a adotar, em escala nacional, um esquema de PSA, no ano de 1997 (MATTEI; ROSSO, 2014).

\section{PSA: DA ABORDAGEM COASEANA PARA A MULTICÊNTRICA}

No marco conceitual de Wunder (2005), os programas de PSA são considerados instrumentos de mercado concebidos para que externalidades positivas na provisão de serviços ecossistêmicos sejam compensadas. A base da ferramenta são os contratos voluntários que regem transações econômicas entre compradores e vendedores de serviços ecossistêmicos. Esses incentivos positivos refletem princípios da economia neoclássica, mais especificamente princípios como utilitarismo, ênfase no livre mercado, teoria de escolha do consumidor e as predições positivas do Teorema de Coase (FAO, 2011).

De acordo com a teoria neoclássica, em que as relações são regidas pelo mercado, espera-se que os indivíduos tenham o seguinte comportamento: ajam movidos pelo interesse próprio, de forma racional, visando maximizar sua satisfação; suas ações sejam racionais, pois são baseadas em informações completas e previsões confiáveis sobre a probabilidade de possíveis resultados; eles têm um conjunto de preferências único, estável e invariável, que é internamente consistente e bem estruturado; eles têm preferências cuja força pode ser medida pela sua disposição a pagar por um grau de satisfação ou disposição a aceitar uma compensação por um benefício perdido (CHEE, 2004).

A competição de mercado muitas vezes não ocorre apenas dentro das regras do jogo, mas sim uma luta pelas próprias regras do jogo, na tentativa de obter vantagens para si, principalmente nas questões de regulamentações e direitos de propriedade. A competição é pelo Estado, para obter vantagens como intervenções, tarifas preferenciais, patentes, regulamentos, compras públicas de equipamento, ajuda para pesquisa-desenvolvimento, ajuda para criação de emprego, modernização, exportação etc. O mercado é uma construção social e uma estrutura de relações, em que os agentes no jogo podem controlar e orientar o Estado buscando impor regras a seu favor (BOURDIEU, 1997).

A premissa do sujeito atomizado, egoísta e totalmente racional foi totalmente rejeitada por pesquisas empíricas. O sujeito não vive em um mundo separado dos demais, está incorporado em redes, organizações, sociedades e em relações com outros indivíduos. E, embora existam indivíduos que estejam preocupados apenas com o próprio bem-estar, há uma proporção significante de pessoas cujo comportamento está voltado para as preocupações da comunidade (OSTROM; AHN, 2007).

Conforme Simões e Andrade (2013), a narrativa de PSAs é de que esquemas "auto-organizados" têm maior eficiência (mais custo efetivo e menos agentes envolvidos) do que programas organizados pelos governos (que buscam outros objetivos simultâneos como a redução da pobreza rural, por exemplo). No entanto os autores advertem que diversos trabalhos recentes criticam a simplificação teórica excessiva e que há um profundo distanciamento entre a abordagem 
normativa, que prevê simples negociações contratuais, e a realidade das condições práticas da aplicação dos mecanismos, que exige configurações e arranjos complexos.

Segundo Pascual et al. (2009), a interpretação dominante dos esquemas de PSA, que o consideram um mero instrumento de mercado para internalizar externalidades negativas, negligencia as complexas interações de relações de poder entre os diversos agentes na construção dos arranjos sociais em que a participação popular é feita, muitas vezes, apenas pela participação dos governos, cujas agendas de políticas públicas não são neutras nem necessariamente populares.

De acordo com Simões e Andrade (2013), os programas de PSA são formados em boa parte por arranjos institucionais com base regulatória, e não necessariamente em puros incentivos ou em mercados, culminando no fato de que tais esquemas não podem ser analisados segundo seu marco teórico convencional. Levantamento realizado por Brouwer, Tesfaye e Pauw (2011), no intuito de descobrir informações quantitativas de esquemas de PSA, identificou que faltam evidências empíricas comprovando a eficácia do programa, que os esquemas voluntários não apresentam bons resultados e, embora seja propagandeado que os acordos são voluntários, 20\% dos casos analisados possuíam práticas mandatórias.

Embora o setor privado esteja aumentando seu envolvimento na maioria dos esquemas de PSAs, o maior comprador continua sendo o setor público, pois tem disponibilidade para levantar fundos em níveis nacionais e internacionais e age em nome da sociedade para preservar serviços ecossistêmicos e promover a sustentabilidade (FAO, 2011). Para Blanchard, Vira e Briefer (2015), a própria narrativa do caso Catskill induz ao erro de propagar o PSA como uma ferramenta de puro mercado coaseana. Os autores afirmam que a popularidade e o poder da narrativa para promover a preservação de ecossistemas com base em um puro instrumento de mercado não condizem com a realidade, pois a Catskill é um caso híbrido, ou seja, de arranjo interinstitucional entre entes públicos e privados, com forma regulatória (em que prevalece o princípio poluidor-pagador) e em parte voluntária (em que prevalece o princípio provedor-recebedor).

Segundo o Ministério do Meio Ambiente (MMA) (BRASIL, 2017) e Pascual et al. (2009), há muita incerteza nas informações ligadas aos programas. Brouwer, Tesfaye e Pauw (2011) asseveram que a eficiência e os resultados científicos ligados aos aspectos de conservação são difíceis de se comprovar na prática. Costanza e Folke (1997) reforçam o argumento ao apontar que, na dimensão econômica do PSA, necessita-se de pouco input científico, ao passo que, na dimensão ecológica, a necessidade é alta, e, na dimensão social, o nível exigido é intermediário.

Conforme Simões e Andrade (2013), a conceituação original de Wunder (2005) não é aplicável, pois a geração de recursos pode requerer abordagens não voluntárias; os SAs são de difícil definição, e os pagamentos podem ser condicionados mesmo em casos de altos custos de transação. Dessa forma é necessário atenção a estes programas como um instrumento multiobjetivado, que faça parte de um mix de políticas indutivas que envolvam um arranjo institucional amplo.

O trabalho de Ostrom (1990) demonstrou que há formas alternativas e eficientes de lidar com o problema da gestão dos recursos de propriedade comum. Para a autora estadunidense, ligada ao institucionalismo, é possível administrar recursos complexos se houver um grande esforço da comunidade e a construção de arranjos institucionais ${ }^{4}$ que objetivem evitar que ocorra o fenômeno de exploração demasiada de bens comunais.

\footnotetext{
${ }^{4}$ Arranjos institucionais são aqueles feitos entre diferentes agentes econômicos que criam uma forma de cooperarem ou competirem na administração de determinado objeto e podem proporcionar uma mudança nas leis ou direitos de propriedade (WILLIAMSON, 1991).
} 
A complexidade de muitos recursos naturais demanda sistemas de governança sofisticados. Quanto mais complexo for o recurso, mais desafiador é criar um arranjo institucional para administrá-lo de forma que forneça incentivos que evitem a superexploração do bem (OSTROM, 1990). É imperativo que os indivíduos se relacionem uns com os outros, e a confiança é uma condição para a democracia e a economia. As redes de relacionamento, as instituições e as considerações sobre o que é socialmente justo afetam a probabilidade de os indivíduos cooperaram em situações de ação coletiva (OSTROM; AHN, 2007).

O indivíduo, em qualquer sociedade, não está fora das teias de relações sociais, ele é parte de uma comunidade e sociedade de quem herdou as instituições e todo o legado civilizatório. Sua participação na gestão dos bens comuns é de grande importância, para que seja construído um mundo melhor para as gerações futuras. Nesse contexto, de governança comum e arranjo institucional, é que mecanismos de PSA podem encontrar o terreno fértil para bons resultados como políticas ambientais.

\section{METODOLOGIA}

Os dados do presente trabalho foram obtidos por meio de pesquisa documental, feita a partir de documentos de órgãos públicos e privados ou com pessoas envolvidas nos projetos, cujo ponto forte está no fato de os documentos serem "uma fonte não reativa" ao pesquisador. Nesse tipo de pesquisa, três aspectos devem ser considerados: a escolha dos documentos, o acesso a eles e a análise dessa documentação (VERGARA, 1998).

Devido ao fato de que o centro de pesquisa dos autores está localizado na Região CentroOeste do Brasil, a escolha dos projetos recaiu sobre projetos que estão localizados na região citada. Dessa forma, foi realizada uma varredura na base de dados da CAPES (SciELO e Web of Science) para consulta de trabalhos que cruzassem os temas PSA e Região Centro-Oeste. Contudo nenhum resultado foi encontrado. Foi efetuada, então, a coleta de dados por meio de pesquisa em documentos disponíveis dos programas (sites, editais, leis). De acordo com o site do Programa Produtor de Água da ANA, os projetos localizados na Região Centro-Oeste são: a) Projeto Guariroba, MS; b) Projeto Pipiripau, DF; c) Projeto João Leite, GO; e d) Projeto Rio Verde, GO. No entanto não foram localizados sites ou quaisquer documentos dos projetos existentes no estado de Goiás, e, por esse motivo, eles foram desconsiderados para a análise. Sendo assim, os casos escolhidos como objeto desta pesquisa são: Projeto Guariroba (MS) e Projeto Pipiripau (DF).

\subsection{Análise da efetividade dos programas}

De acordo com Santos e Silvano (2016) e Engel et al. (2008), para avaliar se programas de PSA estão atingindo seus objetivos, é necessário considerar a presença ou ausência dos seguintes fatores: adicionalidade, vazamento, permanência e custos de transação e oportunidade.

\footnotetext{
${ }^{5}$ Disponível em: https://www.ana.gov.br/programas-e-projetos/programa-produtor-de-agua/projetos, acesso em 4 set. 2019.
} 
Tabela 1-Classificação quanto ao tipo de indicador utilizado

\begin{tabular}{l|l}
\hline \multicolumn{1}{c|}{ Tipo de Indicador } & \multicolumn{1}{c}{ Definição } \\
\hline Adicionalidade & $\begin{array}{l}\text { O programa de PSA deve resultar em açães que induzam a mudanças no uso } \\
\text { da terra ou água, por parte dos proprietários rurais. }\end{array}$ \\
\hline $\begin{array}{l}\text { Custo de } \\
\text { oportunidade }\end{array}$ & $\begin{array}{l}\text { Custo de oportunidade corresponde ao ônus de se deixar de produzir parte } \\
\text { do bem X para se produzir mais do bem Y. Representa o custo da produção } \\
\text { alternativa sacrificada. }\end{array}$ \\
\hline Custo de transação & $\begin{array}{l}\text { Todos os custos que não são os pagamentos propriamente ditos, } \\
\text { por exemplo: custos de informação, negociação (entre vendedores e } \\
\text { compradores), monitoramento, controle, fiscalização e validação dos serviços } \\
\text { providos durante o período de execução do projeto. }\end{array}$ \\
\hline Permanência & $\begin{array}{l}\text { Continuidade da prestação do serviço ambiental, mesmo após o } \\
\text { encerramento dos pagamentos. }\end{array}$ \\
\hline Vazamento & $\begin{array}{l}\text { Ocorre quando as atividades que geram externalidades ambientais negativas } \\
\text { são deslocadas para áreas onde o programa de PSA não foi implementado. }\end{array}$ \\
\hline
\end{tabular}

Fonte: Santos e Silvano (2016).

Além dos itens previstos na literatura, este trabalho buscou também avaliar se há, na documentação, informação a respeito de: 1) arranjo institucional de cada projeto; 2) condicionalidade (se os pagamentos são feitos observando algum critério ambiental); 3) método de monitoramento das ações; e 4) montante de pagamentos e contratos efetuados.

Para proceder com a análise e considerando apenas os aspectos documentais, uma vez que a transparência de órgãos públicos é, em si, um atributo (ou aspecto) de avaliação, consideramos para fins de análise a existência ou não da informação na documentação pública dos projetos.

\section{RESULTADOS}

Neste capítulo, dividido em quatro partes, são apresentados os resultados obtidos na pesquisa.

\subsection{O Programa Produtor de Água}

O Programa Produtor de Água foi criado pela ANA, baseado no conceito provedor-recebedor, e estabeleceu o mercado de PSA no país de forma consistente. O programa visa compensar financeiramente os produtores, para que estes realizem serviços de manutenção e recuperação de áreas em suas propriedades (MATTEI; ROSSO, 2014). Trata-se de um instrumento da União que busca executar ações nas propriedades rurais com vistas à "redução da erosão e do assoreamento de mananciais, de forma a proporcionar o aumento da qualidade e a tornar mais regular a oferta da água" (ANA, 2012, p. 5).

A efetivação do programa se dá por intermédio de uma ponte institucional que articula as diversas esferas públicas com a iniciativa privada e objetiva o desenvolvimento da política de PSA por meio de contratos de adesão voluntária dos produtores rurais. Em seu manual operativo, a ANA discrimina que os projetos devem ser desenvolvidos por um arranjo formado pelos seguintes elementos: 
Figura 2 - Arranjo institucional PSA

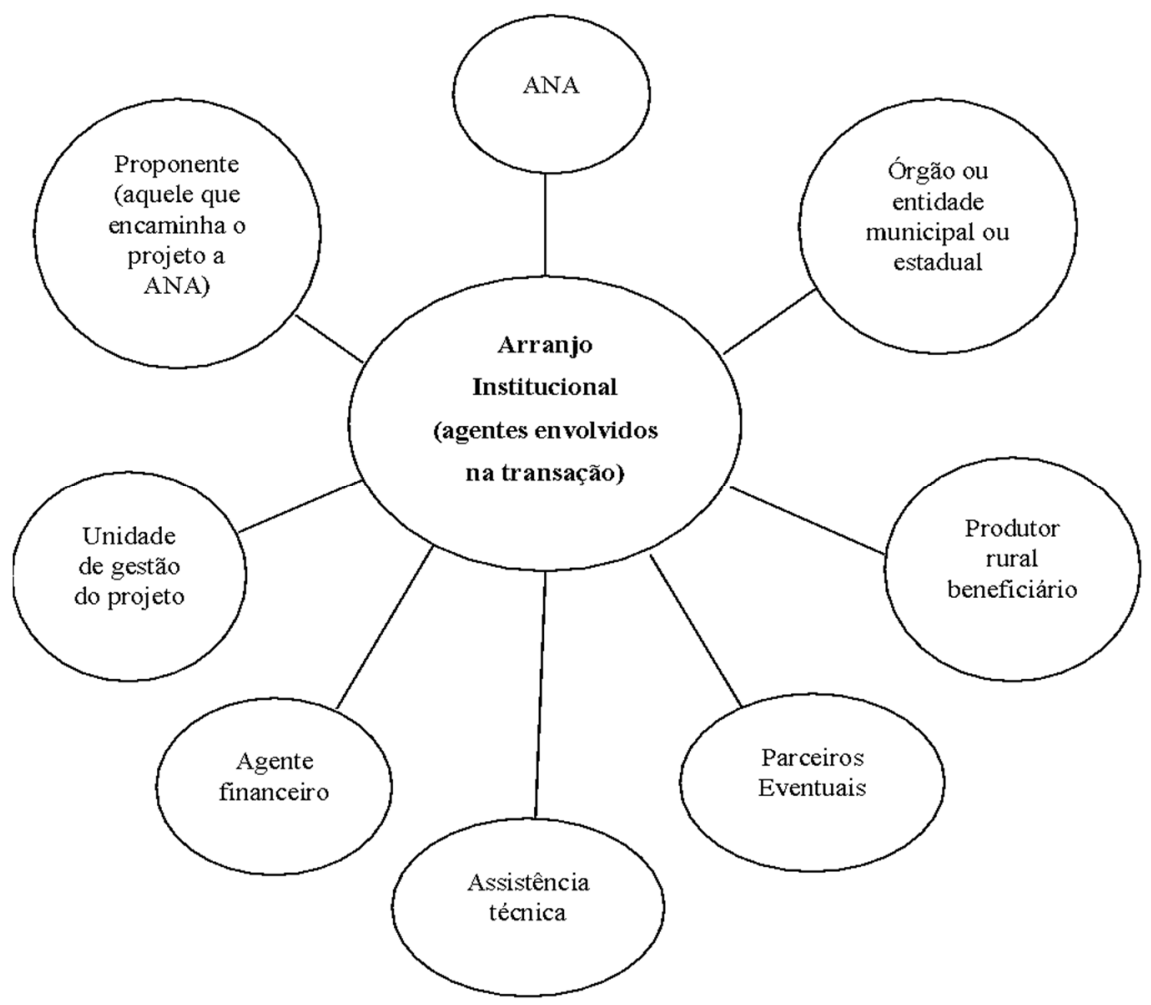

Fonte: Baseado em ANA (2012).

O principal objetivo do programa é a conservação dos recursos hídricos no Brasil, visando promover a ampliação e melhoria da oferta de água, além da regularização da vazão dos corpos hídricos, mediante apoio a projetos de PSA.

Quadro 1 - Projetos do Programa Produtor de Água (região, nome e localização)

\begin{tabular}{|c|c|}
\hline Região & Nome do projeto (Município/Estado) \\
\hline Norte & Brasil Novo (Brasil Novo, PA) \\
\hline Nordeste & Canindé (Canindé do São Francisco, SE) \\
\hline Centro-Oeste & $\begin{array}{l}\text { Pipiripau (Brasília, DF); João Leite (Goiânia, GO); Rio Verde (Rio Verde, GO); Manancial } \\
\text { Vivo (Campo Grande, MS) }\end{array}$ \\
\hline Sudeste & $\begin{array}{l}\text { Capivari (Bom Despacho, MG); Ambrósio (Capitólio, MG); Cajuru (Carmo do Cajuru, } \\
\text { MG); Perobas (Doresópolis, MG); Extrema (Extrema, MG); Santuário das Águas } \\
\text { (Formiga, MG); Guardião dos Igarapés (Igarapé, MG); Nova Serrana (Nova Serrana, } \\
\text { MG); Bocaina (Passos, MG); Oásis (Pimenta, MG); Araras (Piumhi, MG); Bacia do Rio } \\
\text { Mutum (Uberaba, MG); Rio Sesmaria (Resende, RJ); Bacia do Rio Batalha (Bauru, SP); } \\
\text { Bacia Jaguariúna (Jaguariúna, SP); PCJ (Joanópolis e Nazaré Paulista, SP); Ribeirão } \\
\text { Lajeado (Penápolis, SP); Salesópolis (Salesópolis, SP); Mais Água (São José dos } \\
\text { Campos, SP). }\end{array}$ \\
\hline Sul & Camboriú (Camboriú e Balneário Camboriú, SC); Vera Cruz (Vera Cruz, RS) \\
\hline
\end{tabular}

Fonte: Dados da ANA (2012).

A maior concentração dos 27 projetos contemplados pelo Programa Produtor de Água está na Região Sudeste, com um total de 19 projetos, seguida da Centro-Oeste, com quatro projetos; do Sul, com dois projetos; e Norte e Nordeste, com um projeto cada uma das regiões. 


\subsection{Programa Manancial Vivo - Projeto Guariroba ${ }^{6}$}

A Área de Proteção Ambiental dos Mananciais do Córrego Guariroba, também chamada de APA do Guariroba, foi instituída pela Prefeitura Municipal de Campo Grande por meio do Decreto n. 7.182, de 21 de dezembro de 1995. A criação da APA estava vinculada à necessidade de recuperação e conservação do sistema de água bruta para abastecimento do município. A cidade possui, além da APA Guariroba, mais outras duas, a saber: a APA dos Mananciais do Córrego Lajeado e a APA da Bacia do Córrego Ceroula.

Um estudo encomendado pela empresa concessionária Águas Guariroba concluiu, durante processo de análise da bacia, que perdas de solo são causadas pela falta de práticas conservacionistas adequadas de solo e pela fragilidade associada ao meio físico. O sistema de abastecimento de água da cidade de Campo Grande é totalmente operado pela concessionária Águas Guariroba S/A, e a APA Guariroba responde por aproximadamente 50\% do abastecimento de água do município. A localização da bacia está totalmente situada no município de Campo Grande, a aproximadamente 35 quilômetros do centro da capital. A área total da APA é de $360 \mathrm{~km}^{2}$ e é formada, essencialmente, de propriedades rurais voltadas às atividades pecuárias, sendo mais de $82 \%$ da área ocupados por pastagens artificiais.

As propriedades rurais localizadas no território da APA são, em grande parte, de médio e grande porte, tendo na atividade pecuária a principal atividade desenvolvida, predominantemente a bovino de corte, e parte das grandes e médias propriedades são empresas rurais, como frigoríficos e abatedouros. As atividades de manejo do gado, substituindo vegetação natural pelas pastagens cultivadas, gerou, em algumas situações, impactos ambientais expressivos na bacia, pois são incompatíveis com a capacidade de suporte ambiental. Entre os anos de 1985 e 2005, foram desmatados aproximadamente 30\% da área total da bacia do córrego Guariroba, cerca de 13.550 hectares, para atividade de pecuária bovina.

Em decorrência das reuniões e dos estudos, e seguindo os conceitos e as diretrizes do Programa Produtor de Água da ANA, foi desenvolvido pela Prefeitura Municipal de Campo Grande o Programa Manancial Vivo, que é um programa voluntário de restauração do potencial hídrico e do controle da poluição difusa no meio rural.

O programa foi instituído em novembro de 2010, por meio da resolução n. 004, e tem como objetivo viabilizar recursos para a execução de projetos e propor ações de conservação e recuperação de áreas degradadas em bacias hidrográficas, entre outros. Trata-se de um projeto- piloto de PSA para as áreas de proteção ambiental do Guariroba e do Lajeado, ambas situadas na cidade e importantes mananciais de abastecimento público da região.

O ambiente institucional necessário para que o programa tivesse início foi estabelecido pelo Decreto 11.303, de setembro de 2010, da Prefeitura Municipal de Campo Grande, que instituiu o programa de PSA direcionado aos proprietários rurais no município. O objetivo do projeto é recompensar financeiramente o proprietário rural pela prestação de serviços ecossistêmicos abrangendo as seguintes modalidades:

\footnotetext{
${ }^{6}$ Disponível em: http://www.campogrande.ms.gov.br/semadur/canais/manancial-vivo/, acesso em: 20 dez. 2017. A descrição dos itens e etapas desse projeto estão no Plano de Manejo (CAMPO GRANDE, 2008), no Edital 001/2010 (CAMPO GRANDE, 2010) e no Programa Manancial Vivo, resultados obtidos entre 2009 e 2011 (CAMPO GRANDE, 2012).
} 
I. Conservação e melhoria da qualidade e da disponibilidade hídrica;

II. Conservação e incremento da biodiversidade;

III. Redução dos processos erosivos;

IV. Fixação e sequestro de carbono para fins de minimização dos efeitos das mudanças climáticas globais.

\subsection{Projeto Pipiripau ${ }^{7}$}

Em 2001, a Companhia de Saneamento do Distrito Federal (CAESB) encomendou um estudo, em que foi elaborada uma proposta de zoneamento ambiental da bacia hidrográfica do ribeirão Pipiripau, que abastece cerca de 180.000 pessoas do município de Planaltina, e a maior demanda de água é para irrigação.

Foi realizado diagnóstico ${ }^{8}$ socioambiental da bacia hidrográfica prevendo a implantação do Programa Produtor de Água para o Distrito Federal, tendo como objetivo o fomento de ações de integração de gestão de recursos hídricos com as de uso do solo, de conservação de água e solo, revitalização e proteção dos recursos hídricos. De acordo com o relatório, a bacia hidrográfica apresentava uma grande oportunidade para implementar um projeto de PSA devido às suas características para revitalização ambiental, tais como: alto grau de degradação ambiental, conflito pelo uso da água, entre outros.

Entre as ações previstas estavam a recuperação e averbação das áreas de reserva legal, proteção aos fragmentos florestais preservados, incentivo à utilização de práticas agrícolas menos impactantes e de uso racional da água, execução de obras de conservação de solo nas áreas produtivas e estradas vicinais, recuperação das matas ciliares degradadas e pagamento aos produtores rurais participantes pelo serviço ambiental gerado. As ações visavam sobretudo à contribuição de abastecimento de água para a região e regularização ambiental das propriedades rurais, incremento do volume do lençol freático em decorrência do favorecimento da infiltração da água no solo, aumento da vazão do rio nos períodos de estiagem e a redução da turbidez da água.

Com vistas a implantar o projeto de PSA na bacia do Pipiripau, foi celebrado, em dezembro de 2011, um Acordo de Cooperação Técnica (ACT) ${ }^{9}$ entre diversos atores, cujo objetivo era integração de esforços para desenvolver o programa produtor de água na bacia hidrográfica. Posteriormente ao acordo de cooperação técnica firmado, foi lançado, em janeiro de 2012, o Edital que estabelecia a operação do PSA e colocava o programa em funcionamento. Cabe citar que não foi encontrada uma lei específica para a operacionalização do PSA na bacia do Pipiripau, o seu funcionamento ocorreu de acordo com o edital. O edital previa contratos com o prazo máximo de cinco anos. Em 2017, foi lançado um novo edital, com pequenas alterações.

\footnotetext{
${ }^{7}$ Disponível em: http://www.produtordeaguapipiripau.df.gov.br/, acesso em: 20 dez. 2017. A descrição dos itens e etapas desse projeto estão em CAESB (2001) e nos editais da Agência Reguladora de Águas, Energia e Saneamento Básico do Distrito Federal (ADASA, 2012; 2017).

${ }^{8}$ Disponível em: http://produtordeagua.ana.gov.br/Portals/O/DocsDNN6/Seminario_Marco_2015/diagnostico-prodagua-piripau.pdf, acesso em: 20 dez. 2017.

${ }_{9}^{9}$ Acordo de cooperação técnica 015/ANA/2011, disponível em: http://produtordeagua.ana.gov.br/Portals/0/ DocsDNN6/documentos/ACT_pipiripau_assinado.pdf, acesso em: 9 jan. 2018.
} 


\subsection{Avaliação dos esquemas}

Em consonância com os objetivos deste trabalho e com a metodologia anteriormente exposta, os programas serão primeiramente analisados sob os aspectos da adicionalidade, ou seja, se as ações realmente induziram a mudanças de atividades na área contratada que levaram a serviços ambientais os quais geraram conservação ou aumento dos recursos ambientais, se comparados à ausência dos incentivos (SIMÕES; ANDRADE, 2013). De acordo com Wunder (2005), adicionalidade para mercados de carbono é aceita em casos em que há florestamento e reflorestamento. Dessa forma, pode-se extrapolar tal aspecto para casos de recursos hídricos.

Tabela 2 - Avaliação dos Esquemas de PSA

\begin{tabular}{l|c|c}
\multicolumn{1}{c|}{ Item } & Guariroba & Pipiripau \\
\hline Adicionalidade & 1 & 1 \\
\hline Vazamento & n/a & n/a \\
\hline Permanência & 0 & 0 \\
\hline Custos de transação & 0 & 0 \\
\hline Oportunidade & 1 & 1 \\
\hline
\end{tabular}

Síntese dos indicadores avaliados $(0$ = ausência do indicador; 1 = presença do indicador; N/A = não avaliado).

Fonte: Dados da pesquisa.

Os dados levantados não apresentam verificação de vazamento, visto que o monitoramento que ocorre nos programas de PSA é realizado somente nas áreas destinadas aos projetos, representando uma falha de tais programas em detectar esse tipo de problema. Com relação aos custos de oportunidade, verificou-se que, em ambos os projetos, a atividade pecuária por hectare foi utilizada como simulação para remuneração aos produtores. Não há menção nos projetos a respeito dos custos de transação. Quanto à permanência, os editais têm datas-limite, portanto verifica-se a ausência desse quesito.

Tabela 3 - Elementos dos Programas de PSA

\begin{tabular}{|c|c|c|}
\hline Componentes & Guariroba & Pipiripau \\
\hline Arranjo Institucional & $\begin{array}{l}\text { Prefeitura Municipal de Campo } \\
\text { Grande, ANA, Unidade de } \\
\text { Gestão do Projeto (UGP), } \\
\text { Secretaria Municipal de Meio } \\
\text { ambiente e Desenvolvimento } \\
\text { Humano (SEMADUR), Banco do } \\
\text { Brasil (BB), Fundação Branco do } \\
\text { Brasil (FBB) e World Wide Fund } \\
\text { for Nature (WWF-Brasil). }\end{array}$ & $\begin{array}{l}\text { UGP, ADASA, ANA, Ministério } \\
\text { da Integração Nacional; CAESB, } \\
\text { Secretaria de Estado de Agricultura } \\
\text { e Desenvolvimento Rural do Distrito } \\
\text { Federal (SEAGRI), Instituto Brasília } \\
\text { Ambiental (IBRAM), Empresa de } \\
\text { Assistência Técnica e Extensão Rural } \\
\text { do Distrito Federal (EMATER), FBB, } \\
\text { BB, Fundação Universidade de Brasília } \\
\text { (FUB), The Nature Conservancy } \\
\text { (TNC), WWF-Brasil e Serviço Social da } \\
\text { Indústria (SESI). }\end{array}$ \\
\hline Critérios de Remuneração & $\begin{array}{l}\text { 1. Conservação de água e solo; } \\
\text { 2. Restauração ecológica em } \\
\text { APP; } \\
\text { 3. Conservação de fragmentos } \\
\text { florestais. }\end{array}$ & $\begin{array}{l}\text { 1. Conservação do solo; } \\
\text { 2. Restauração ou conservação de APP } \\
\text { e/ou Reserva Legal; } \\
\text { 3. Conservação de remanescentes de } \\
\quad \text { vegetação nativa. }\end{array}$ \\
\hline
\end{tabular}




\begin{tabular}{l|l|l}
\hline \multicolumn{1}{c|}{ Componentes } & \multicolumn{1}{c|}{ Guariroba } & \multicolumn{1}{c}{ Pipiripau } \\
\hline Monitoramento e Medição & Semestralmente & Semestralmente \\
\hline $\begin{array}{l}\text { Condicionalidade } \\
\begin{array}{l}\text { Montante de pagamentos } \\
\text { e contratos efetuados }\end{array}\end{array}$ & Sim & São encontrado \\
\hline
\end{tabular}

Fonte: Dados da pesquisa.

Embora tenham sido encontradas informações a respeito das cláusulas contratuais e de como funcionam os programas nos editais, informações referentes à evolução dos contratos e dos valores pagos aos produtores ao longo dos anos dos programas implantados não estão disponíveis na documentação. É fundamental que informações dessa natureza sejam divulgadas para que interessados em políticas públicas possam fazer análises mais profundas a respeito dos gastos que envolvem políticas dessa natureza.

\section{CONSIDERAÇÕES FINAIS}

Os programas de PSA vêm ganhando espaço nos debates sobre conservação e recuperação de ambientes naturais no Brasil. Este instrumento de gestão ambiental reconhece o valor econômico da proteção de ecossistemas e dos usos sustentáveis e promove um incentivo econômico aos "provedores" de serviços ambientais.

Este trabalho objetivou analisar os elementos institucionais que formam um mercado de PSA e sua utilização como ferramenta de política pública ambiental. A pesquisa procurou responder se é possível verificar empiricamente que os esquemas de PSA analisados corroboram a narrativa de mercado e a perspectiva coaseana que sustenta os trabalhos teóricos a respeito de PSA. Foram analisados dois projetos, um no estado de Mato Grosso do Sul (projeto Guariroba) e outro no Distrito Federal (projeto Pipiripau).

Observou-se que, embora a narrativa dominante seja a da perspectiva coaseana e a de que o mercado pode, por si, resolver questões complexas, tal embasamento teórico não sustenta a realidade concreta materializada nos casos de PSA analisados. O programa é elaborado e coordenado por uma agência reguladora e recebe incentivos governamentais, além de mecanismos de comando e controle. Há o compartilhamento de gestão entre diferentes instituições por meio de comitês, que contam com a participação da sociedade civil e que podem, inclusive, ajudar a financiar parcial ou integralmente um projeto. A participação de diversos atores no arranjo social e as regras contempladas por contrato ou pelas relações estabelecidas formaram as instituições que dão estabilidade e reduzem as incertezas dos arranjos de PSA analisados nesta pesquisa. Nesse sentido, percebe-se que os mecanismos encontrados de PSA se aproximam muito mais da perspectiva de Ostrom, sobre diversidade de atores, papéis multicêntricos e arranjos institucionais, do que da perspectiva coaseana.

Os projetos apresentaram aspectos positivos. Porém faltam algumas informações na documentação oficial dos programas quanto aos resultados obtidos. Recomenda-se que essas informações sejam publicadas para que haja maior transparência e esses programas possam ser comparados com outras formas de manutenção do bem ecossistêmico.

Há uma necessidade de consolidar o arcabouço teórico do PSA, a partir do acompanhamento e avaliação dos projetos ao longo dos anos. Pesquisas mostrando a evolução após os primeiros 
anos podem ajudar na adaptação, na redução dos custos de monitoramento e das incertezas, na melhoria das salvaguardas e no melhoramento das bases estratégicas dos programas de PSA. Os resultados dessas primeiras experiências em projetos de PSA podem auxiliar na evolução dos cenários futuros da gestão de recursos hídricos sob a perspectiva do desenvolvimento rural conservacionista e produtivo.

Por último, cabe ressaltar que definições de direito de propriedade não são neutras do ponto de vista de valores sociais e da desigualdade, e tais questões não podem ser negligenciadas. A narrativa dominante dos esquemas de PSA é a de mercado como solução para questões ambientais, contudo, conforme visto no trabalho, os esquemas em geral possuem múltiplas determinações. Os programas de PSA reiteram e fortalecem o conceito de propriedade privada acima de questões outras. Em países onde há conflitos por terras, tal advertência deve ser altamente considerada. Seria possivelmente mais proveitoso mudar a perspectiva da remuneração da propriedade privada do bem ecossistêmico para uma perspectiva que baseia a remuneração no trabalho: o serviço ambiental.

\section{REFERÊNCIAS}

AGÊNCIA REGULADORA DE ÁGUAS, ENERGIA E SANEAMENTO BÁSICO DO DISTRITO FEDERAL [ADASA]. Edital n. 01/2017. Pagamento por serviços ambientais a produtores rurais da Bacia do Pipiripau. Brasília-DF, jul. 2017.

AGÊNCIA REGULADORA DE ÁGUAS, ENERGIA E SANEAMENTO BÁSICO DO DISTRITO FEDERAL [ADASA]. Edital n. 01/2012. Pagamento por serviços ambientais a produtores rurais da Bacia do Pipiripau. Brasília-DF, ago. 2012. Disponível em: http://produtordeagua.ana.gov.br/Portals/O/DocsDNN6/ Seminario_Marco_2015/Edital\%20ADASA\%20\%201_2012\%20Pagamento\%20por\%20Servi\%C3\%A7os\%20 Ambientais_RETIFICA\%C3\%87\%C3\%830\%202.pdf. Acesso em: 20 dez. 2017.

AGÊNCIA NACIONAL DE ÁGUAS [ANA]. Manual operativo do Programa Produtor de Água. 2. ed. Brasília-DF: ANA, 2012.

BLANCHARD, L.; VIRA, B.; BRIEFER, L. The lost narrative: ecosystem service narratives and the missing Wasatch watershed conservation story. Ecosystem Services, [s.l.], v. 16, p. 105-11, 2015. Disponível em: https://www.repository.cam.ac.uk/handle/1810/252456. Acesso em: 29 ago. 2017.

BOURDIEU, P. Le champ économique. Actes de la Recherche en Sciences Sociales, Économie et Économistes, [s.l]., v. 119, p. 48-66, 1997.

BRASIL. Ministério do Meio Ambiente [MMA]. Instrumentos econômicos. Brasília-DF: MMA, 2017. Disponível em: http://www.mma.gov.br/governanca-ambiental/economia-verde/instrumentos-econ\%C3\%B4micos. Acesso em: 9 maio 2017.

BROUWER, R.; TESFAYE, A.; PAUW, P. Meta-analysis of institutional-economic factors explaining the environmental performance of payments for watershed services. Environmental Conservation, [s.l.], v. 38, n. 4, p. 380-92, 2011.

CAMPO GRANDE (Cidade). Secretaria Municipal do Meio Ambiente e Gestão Urbana (SEMADUR). Programa Manancial Vivo - aspectos conceituais, metodológicos e resultados obtidos entre os anos de 2009 a 2011. Campo Grande, MS: SEMADUR, 2012. Disponível em: http://www.campogrande.ms.gov.br/semadur/ downloads/programa-manancial-vivo-relatorio-2009-a-2011/. Acesso em: 15 dez. 2021 
CAMPO GRANDE (Cidade). Edital n.01/2010. Programa Manancial Vivo - PMV. Regras para o credenciamento de proprietários rurais visando a seleção de propostas destinadas a conservação de solo, água e florestas e ao recebimento de pagamento por serviços ambientais no município de Campo Grande. Campo Grande, MS, 2010. Disponível em: http://produtordeagua.ana.gov.br/Portals/0/DocsDNN6/documentos/ Edital_001_2010_PMV.pdf. Acesso em: 30 nov. 2017.

CAMPO GRANDE (Cidade). Plano de manejo da área de proteção ambiental dos mananciais do córrego Guariroba-APA do Guariroba. Campo Grande, MS, maio 2008. Disponível em: https://www.campogrande. ms.gov.br/semadur/artigos/plano-de-manejo-apa-guariroba/. Acesso em: 9 jan. 2018.

CHEE, Y. E. An ecological perspective on the valuation of ecosystem services. Biological Conservation, Elsevier, v. 120, n. 4, p. 549-65, 2004.

CHOMITZ, K. M.; BRENES, E.; CONSTANTINO, L. Financing environmental services: the Costa Rican experience and its implications. Science of the Total Environmental, Elsevier, v. 240, n. 1, p. 157-69, 1999.

COASE, R. H. The problem of social cost. Journal of Law and Economics, [s.I.], v. 3, p. 1-44, 1960.

COMPANHIA DE SANEAMENTO DO DISTRITO FEDERAL [CAESB]. Plano de proteção ambiental da bacia hidrográfica do ribeirão Pipiripau. Diagnóstico ambiental. Brasília-DF, jul. 2001. Disponível em: http:// produtordeagua.ana.gov.br/Portals/0/DocsDNN6/documentos/Plano\%20Prote\%C3\%A7\%C3\%A30\%20 Pipiripau.pdf. Acesso em: 20 dez. 2017.

COSTANZA, R.; FOLKE, C. Valuing ecosystem services with efficiency, fairness and sustainability as goals. In: DAILY, G. C. (Ed.). Nature's services: societal dependence on natural ecosystems. Washington, D.C.: Island Press, 1997. p 49-70.

DIMAGGIO, P. J.; POWELL, W. W. Introduction. In: DIMAGGIO, Paul J.; POWELL, Walter W. (Ed.). The new institucionalism in organizational analysis. Chicago: University of Chicago Press, 1991.

ENGEL, S.; PAGIOLA, S.; WUNDER, S. Designing payments for environmental services in theory and practice: an overview of the issues. Ecological Economics, Elsevier, n. 65, p. 663-74, 2008.

FOOD AND AGRICULTURE ORGANIZATION OF THE UNITED NATIONS [FAO]. Payments for ecosystems services and food security. Roma: FAO, 2011. Disponivel em: http://www.fao.org/docrep/014/i2100e/ i2100e.pdf. Acesso em: 17 jul. 2017.

GUEDES, F. B; SEEHUSEN, S. E. (Org.). Pagamentos por serviços ambientais na Mata Atlântica: lições aprendidas e desafios. Brasília, DF: MMA, 2011.

HARVEY, D. Condição pós-moderna. São Paulo: Edições Loyola, 2008.

HÖFLING, E. M. Estado e políticas (públicas) sociais. Cadernos Cedes, [s.I.], ano 21, n. 55, 2001.

IKENBERRY, G. J. History's heavy hand. Institutions and the politics of the State. [S.I.]: [s.n.], 1994. Disponível em: http://scholar.princeton.edu/sites/default/files/HistorysHeavyHand_0.pdf. Acesso em: 9 jul. 2017.

LANDEL-MILLS, N.; PORRAS, I. T. Silver bullet or fools' gold? - a global review of markets for forest environmental services and their impact on the poor. Relatório de pesquisa preparado por o Instituto Internacional para o Meio Ambiente e Desenvolvimento (IIED). Londres, mar. 2002.

MATTEI, L; ROSSO, S. Evolução do mercado de pagamento por serviços ecossistêmicos no Brasil: evidências a partir do setor hídrico. Boletim Regional, Urbano e Ambiental, Rio de Janeiro, n. 9, 2014. [IPEA]. 
MILLENIUM ECOSYSTEM ASSESSMENT [MEA]. Ecosystems and human well-being: synthesis. Washington, D.C.: Island Press, 2005.

MUNCK, L.; SOUZA, R. B. A relevância do ser humano no contexto da institucionalização e legitimação do paradigma da sustentabilidade. Revista de Gestão USP, São Paulo, v. 16, n. 3, p. 1-14, 2009.

OSBORNE, D.; GAEBLER, T. Reinventando o governo: como o espírito empreendedor está transformando o setor público. Brasília, DF: MH Comunicação, 1994.

OSTROM, E. Governing the commons: the evolution of institutions for collective action. New York: Cambridge University Press, 1990.

OSTROM, E.; AHN, T. The meaning of Social Capital and its link to collective action. Bloomington, 2007. Disponível em: http://citeseerx.ist.psu.edu/viewdoc/download?doi=10.1.1.472.3769\&rep=rep1\&type= pdf. Acesso em: 28 out. 2017.

PASCUAL, U.; MURADIAN, R.; RODRÍGUEZ, L. C.; DURAIAPPAH, A. K. Revisiting the relationship between equity and efficiency in payments for environmental services. Ecosystem Services Economics (ESE). Ecosystem Services Economics Unit, Division of Environmental Policy Implementation, UNEP, Nairobi, Kenya., 2009. 16 p. [Working Paper Series].

SANTOS, F. L.; SILVANO, R. A. M. Aplicabilidade, potenciais e desafios dos Pagamentos por Serviços Ambientais para conservação da água no sul do Brasil. Desenvolvimento e Meio Ambiente, [s.l.], v. 38, p. 481-98, ago. 2016.

SIMÕES, M.; ANDRADE, D. C. Limitações da abordagem coaseana à definição do instrumento de Pagamento por Serviços Ambientais (PSA). Sustentabilidade em Debate, Brasília, v. 4, n. 1, p. 59-78, jan./jun. 2013.

SOUZA, C. Políticas Públicas: uma revisão da literatura. Sociologias, Porto Alegre, ano 8, n. 16, p. 20-45, jul./dez. 2006.

STERN, N. Stern review on the economics of climate change. Report to the Prime Minister and the Chancellor of the Exchequer, Cabinet Office. London, UK, 2006.

THELEN, K.; STEINMO, S. Historical institutionalism in comparative politics. In: THELEN, K.; STEINMO, S.; LONGSTRETH, F. (Org.). Structuring politics: historical institutionalism in comparative analysis. Cambridge: Cambridge University Press, 1992.

VERGARA, S. C. V. Projetos e relatórios de pesquisa em administração. 2. ed. São Paulo: Atlas, 1998.

WILLIAMSON, O.E. Comparative economic organization: the analysis of discrete structural alternatives. Administrative Science Quarterly, [s.I.], v. 36, n. 2, p. 269-96, 1991.

WUNDER, S. Payments for environmental services: some nuts and bolts. Center for International Forestry Research, Indonesia, n. 42, 2005. Disponível em: http://www.cifor.org/publications/pdf_files/OccPapers/ OP-42.pdf. Acesso em: 20 jul. 2017.

\section{Sobre os autores:}

Fábio Melges: Doutorando em Administração na Universidade Federal de Mato Grosso do Sul (UFMS). Participa do Grupo de Estudos e Pesquisas sobre Organizações, Trabalho e Educação (GEPOTE). E-mail: fabiobmelges@gmail.com, Orcid: http://orcid.org/0000-0001-8914-9925 
Leonardo Francisco Figueiredo Neto: Doutor em Engenharia (Engenharia de Produção) pela Universidade de São Paulo. Professor associado da Universidade Federal de Mato Grosso do Sul (UFMS). Tem experiência na área de Engenharia de Produção, com ênfase em Avaliação de Projetos, atuando nos seguintes temas: analise econômica de projetos, gestão ambiental, agronegócio, logística reversa, sustentabilidade e agricultura familiar. E-mail: Iffneto@gmail.com, Orcid: http://orcid.org/0000-0002-4456-3396

Élcio Gustavo Benini: Doutor em Educação. Professor adjunto da Escola de Administração e Negócios (ESAN) da Universidade Federal de Mato Grosso do Sul (UFMS). Atua no Programa de Pós-Graduação stricto sensu em Administração e no mestrado profissional em Administração Pública (PROFIAP). Participa do Grupo de Estudos e Pesquisas sobre Organizações, Trabalho e Educação (GEPOTE). Tem como temas de estudo e pesquisa: teoria crítica das organizações; epistemologia; economia solidária; autogestão; administração pública; políticas públicas; e trabalho e educação. E-mail: elciobenini@yahoo.com.br, Orcid: http://orcid.org/0000-0002-0949-3062 